\title{
Analysis of the Russian Human Capital Index
}

\author{
Valeriy Smirnov, Vladislav Semenov, Sergei Zimin, Nikolay Golubtsov, and Galina Dulina \\ Chuvash state University, 428015 Cheboksary, Russia
}

\begin{abstract}
The article considers the issue of the Russian economy reaching development limit, what actualizes the need to analyze the human capital index dynamics. The study of the human capital index components dynamics revealed a special priority of state policy. Analysis of the Russian educational system development revealed its feminization, which changes the principles of the modern society formation. A negative change in the Russian educational system was observed in the form of a significant decline in the growth of preschool youth of junior median age and preschool children of younger age, a significant gap in the growth rate of government spending on education (\% of GDP) to spending on education as a percentage of total government spending. In general, the priority of state policy to ensure the survival of male children under 5 years of age and subsequent indifference to their socialization in the Russian educational system with clear signs of feminization escalate the problem of gender bias risk. The Russian economy development, based on the increment of surplus value in the process of exploitation of unskilled labor and the level of wages insufficient for natural reproduction of the latter, has reached its limit.
\end{abstract}

\section{Introduction}

The human capital index (Human Capital Index, HCI) dynamics analysis is relevant because of the limit achieved by the development of the Russian economy based on the increment of surplus value from economies of scale during exploitation of unskilled labor and the level of wages insufficient for the natural reproduction of the latter. The HCI measures the contribution of health care and education to labor productivity, and the HCI value ranges from zero to one and reflects the productivity of the future worker born today, compared with a model for complete health and education.

Transformation of the globalizing world order has intensified competition in the markets and, as a result, has changed the principles and opportunities for the development of the Russian economy.

HCI's informational purpose relates to measuring the human capital that a child born today can potentially accumulate by one's 18th birthday, adjusted for the risk associated with the inadequate quality of health care and education in the country where one lives. Human capital is the knowledge, skills and health that people accumulate during their lives, which allows them to realize their potential as useful society members [1].

Susanna G. Campbell, Murat Üngör draw the scientific community's attention to the need for a complementary assessment of human capital and economic development, taking into account education (years of schooling), cognitive skills (expressed by test results), 
health indicators (for which adult survival rates are used) [2]. Sigitas Vaitkevičius, Rūta Čiutienè, Evelina Meilienè, Asta Savanevičienè proposed a typology of countries according to the level of human capital development, which includes three sub-indices: (1) social progress of human capital; (2) the level of innovative development of human capital; (3) the potential for the development of human capital [3].

Li-Ting Yeh, Ming-Lang Tseng, Ming K. Lim linked human capital, as a result of professional knowledge accumulation, with the possibility of using it for a long time for sustainable economic development [4]. Yunfu Xu, Aiya Li believe that people are carriers of innovation, and innovative human capital is a combination of the human factor and innovation - the basis of the modern economy [5]. Li Ma, Xin Zhai, Weiguo Zhong, ZhiXue Zhang found that the task-specific training and employee participation in companies' innovations implementation, in terms of commercial success, stimulate development of new products and increase percentage of a company revenues from newly developed products [6].

Bosede Comfort Olopade, Henry Okodua, Muyiwa Oladosun, Abiola John Asaleye have shown that natural resources are an obstacle to growth [7]. When studying the impact of abundance of natural resources, human capital and urbanization on the ecological situation and economic growth, Zahoor Ahmed, Muhammad Mansoor Asghar, Muhammad Nasir Malik, Kishwar Nawaz came to the conclusion that the rent for natural resources has a significant impact on the ecological situation. Urbanization and economic growth contribute to environmental degradation, while human capital mitigates environmental degradation [8].

Yao Yao, Kris Ivanovski, John Inekwe, Russell Smyth found that an increase in human capital reduces total energy consumption by $15.36 \%$. An increase in human capital by one standard deviation is associated with a $17.33 \%$ decrease in dirty energy consumption and an $85.54 \%$ increase in clean energy consumption [9].

Ching-Fu Chang, Ping Wang, Jin-Tan Liu point out that the dissemination of knowledge in the form of human capital is often seen as a moving force of sustainable growth and development, namely, a $1 \%$ increase in the share of workers with higher education increases the productivity of enterprises by about $0.93-1.15 \%$ [10].

Mark Gradstein identified a significant cost component associated with investing in human capital, what leads to a reciprocal feedback between the labor market and the skill acquisition market [11]. Balázs Égert, Jarmila Botev, David Turner empirically identified the impact of education policy on HCI. Their findings show that European and OECD countries are characterized by a higher proportion of preschool education, greater autonomy of schools and universities, a low student-to-teacher ratio, a high age of admission to secondary school, and low barriers to funding education [12].

So, the problem of analyzing the dynamics of HCI acquires a global status, capturing not only the limits of the actual development of an individual country economy, but making it possible to assess future position of the latter, thereby choosing the optimal parameters for the transition to the "economy of knowledge".

\section{Methods}

To analyze the dynamics of HCI in Russia, we will apply the methods of cluster and neural network analysis, including the processing of statistical indicators, their systematization and presentation in the form of diagrams and tables. Processing of statistical data is carried out using IBM SPSS Statistics Software, and construction of tables, charts and graphs is carried out using MS Excel.

The use of cluster analysis is due to the addition of the probabilistic understanding of causality with the coherence of changes in the estimated indicators. Cluster analysis 
facilitates collection of data containing information about object retrieval and arrange the objects of research into relatively homogeneous groups. This allows for the development of a classification of objects or phenomena under study, and identification of the main schemes for their grouping and hypotheses formulation.

Neural network analysis allows to identify patterns of change in objects or phenomena by building neural networks. Hypotheses formulated with the help of cluster and neural network analysis will allow to determine the predictive results of the applied management decisions.

\section{Results and discussion}

The data of the World Bank Group (WBG) became basis for the analysis of HCI in Russia. The HCI database provides country-level data for each of the HCI components, including breakdown by gender. HCI measures the amount of human capital that a child born today can expect to reach by age 18, given the risks of ill health and poor education that prevail in the country where one lives. HCI aims to show how improvements in current health care and education outcomes impact the labor productivity of the next generation of workers, assuming that over the next 18 years children born today will experience educational opportunities and health risks children of this age are currently facing.

Cluster analysis of the HCI components growth rates revealed the following: (1) priorities - 'Probability of survival up to 5 years, men'; "Harmonized Test Results"; "Education - Adjusted Years of Schooling"; (2) indifference - HCI, males, lower bound. The lower HCI bound reflects the uncertainty of the components and overall index measurement (Table 1).

Table 1. Clusters of HCI components growth rates, 2011-2020

\begin{tabular}{|c|c|c|}
\hline \multicolumn{2}{|c|}{ Cluster } & $\begin{array}{c}\text { Squared } \\
\text { Euclidean } \\
\text { distance }\end{array}$ \\
\hline \multirow{2}{*}{ HCI, men (scale 0-1) } & HCI (scale 0-1) & 0.54 \\
\cline { 2 - 3 } & Harmonized test scores, women & 1.15 \\
\cline { 2 - 3 } & HCI, women (scale 0-1) & 1.81 \\
\cline { 2 - 3 } & HCI, women, upper bound (scale 0-1) & 17.34 \\
\hline \multirow{2}{*}{ HCI, women, upper bound (scale 0-1) } & HCI upper bound (scale 0-1) & 0.62 \\
\cline { 2 - 3 } & HCI, men, upper bound (scale 0-1) & 1.84 \\
\hline Survival from 15-60 years old, women & Probability of surviving up to 5 years & 0.53 \\
\cline { 2 - 3 } & Expected years of schooling, men & 1.60 \\
\hline Expected years of schooling, men & Expected years of schooling & 0.03 \\
\cline { 2 - 3 } & Expected years of schooling, women & 0.12 \\
\hline Probability of survival up to 5 years, men & Probability of surviving up to 5 years, & 0.00 \\
\hline Probability of surviving up to 5 years & women & 0.00 \\
\hline Harmonized test scores & Harobility of survival up to 5 years, men & 0.04 \\
\hline Schooling - adjusted school years & Schooling - adjusted school years, women & 0.07 \\
\hline Harmonized test scores, women & Harmonized test scores & 0.10 \\
\hline Schooling - adjusted school years, men & Schooling - adjusted school years & 0.19 \\
\hline
\end{tabular}

Note: Hierarchical cluster analysis - the average distance between clusters, the square of the Euclidean distance.

Source: calculated in "IBM SPSS Statistics Software" according to the World Bank Group, All Rights Reserved. Data Catalog. Worldwide Governance Indicators. https://datacatalog.worldbank.org (Access: 2020/11/20).

Thus, the dynamics of HCI components indicates a special priority of the state policy of ensuring the male children under 5 years of age survival and subsequent indifference to their formation. This indifference is based on the danger of formation of a reasonable force capable of changing the existing raw materials market economy, the capitalist socioeconomic formation. 
Analysis of the Russian educational system development is carried out using the WBG data, which contains over 4,000 international comparable indicators describing access to education, stages of education, literacy, teachers, society and costs. As a result of neural network analysis of the Russian educational system indicators growth rates, the feminization of the Russian educational system was revealed. The female gender dominates in high-importance educational positions: (1) admission in primary education; (2) proportion of students in preschool education system; (3) primary education gross coverage ratio; (4) population, age 11-15; (5) admission to the 1st form of incomplete secondary general education; (6) the average length of schooling, from primary to higher education; (7) admission to higher education institutions, all curricula; (8) adjusted net admission rate to the 1 st form of primary education.

The males showed themselves in positions insignificant by importance: (1) gross admission rate, incomplete secondary education; (2) gross admission rate, higher education; (3) population of the age legal for primary education.

In the result of cluster analysis of the Russian educational system growth rates the priorities should be identified (Table 2): (1) the most significant clusters are female, age 2-3 years; (2) compositional - females 3-5 years old and males 4-5 years old. Consequently, the Russian educational system internal movement tendency to feminize is associated with the earlier formation of the female educational cluster.

Table 2. Significant clusters of growth rates of social, economic, and demographic indicators covering the education cycle from preschool to vocational and higher education, $2000-2025$. The median growth rate is greater than zero

\begin{tabular}{|c|c|c|}
\hline $\begin{array}{l}\text { Squared } \\
\text { Euclidean } \\
\text { distance }\end{array}$ & \multicolumn{2}{|c|}{ Weighty clusters (squared Euclidean distance is less than one) } \\
\hline $2.63 \mathrm{E}-03$ & Population, age of 3 , total & Population, age of 3 , females \\
\hline $3.81 \mathrm{E}-03$ & Population, age of 2 , females & Population, age of 2, total \\
\hline 5.89E-03 & Population, age of $3-5$, total & Population, age of 3-5, males \\
\hline $7.21 \mathrm{E}-03$ & Population, age of 4 , females & Population, age of 4, total \\
\hline 9.09E-03 & Population, age of 4-6, total & Population, age of 4-6, males \\
\hline $1.08 \mathrm{E}-02$ & Population, age of 5, females & Population, age of 5 , total \\
\hline $1.17 \mathrm{E}-02$ & $\begin{array}{l}\text { Population of official preschool education } \\
\text { age, both genders (number) }\end{array}$ & $\begin{array}{l}\text { Population of official preschool education } \\
\text { age, males (number) }\end{array}$ \\
\hline $1.57 \mathrm{E}-02$ & Population, age of $3-5$, females & Population, age of $3-5$, total \\
\hline $2.43 \mathrm{E}-02$ & Population, age of 4-6, females & Population, age of 4-6, total \\
\hline $3.08 \mathrm{E}-02$ & $\begin{array}{l}\text { Population of official preschool education } \\
\text { age, females (number) }\end{array}$ & $\begin{array}{l}\text { Population of official preschool education } \\
\text { age, both genders (number) }\end{array}$ \\
\hline $8.41 \mathrm{E}-02$ & $\begin{array}{l}\text { Average length of study, primary and } \\
\text { incomplete secondary school, males (years) }\end{array}$ & $\begin{array}{l}\text { Average length of study, primary and } \\
\text { incomplete secondary school, both genders } \\
\text { (years) }\end{array}$ \\
\hline $1.15 \mathrm{E}-01$ & Population, age of 24 , total & Population, age of 24, females \\
\hline $2.01 \mathrm{E}-01$ & Population, age of 25 , total & Population, age of 25 , females \\
\hline $2.22 \mathrm{E}-01$ & $\begin{array}{l}\text { Average length of study, primary and } \\
\text { incomplete secondary school, females } \\
\text { (years) }\end{array}$ & $\begin{array}{l}\text { Average length of study, primary and } \\
\text { incomplete secondary school, males (years) }\end{array}$ \\
\hline $3.68 \mathrm{E}-01$ & Population, age of 5, males & Population, age of 4-6, females \\
\hline $5.57 \mathrm{E}-01$ & Population, age of $3-5$, females & Population, age of 4, males \\
\hline $8.92 \mathrm{E}-01$ & Population, age of 5 , females & Population, age of 5 , males \\
\hline
\end{tabular}

Note: Hierarchical cluster analysis - the average distance between clusters, the square of the Euclidean distance.

Source: calculated in "IBM SPSS Statistics Software" according to the World Bank Group, All Rights Reserved. Data Catalog. Worldwide Governance Indicators. https://datacatalog.worldbank.org (Access: 2020/11/20).

Analysis of the growth rates of the development of the Russian educational system using data from the UNESCO Institute for Statistics [13] revealed a significant decrease in the growth of preschool juveniles of younger median age and preschool children of early age. Against this background, there is a positive trend towards a decrease in the growth rate 
of the proportion of younger children, children and juveniles who do not attend school. It was also found that the growth rates of government spending on education (\% of GDP) [14] lagged behind spending on education as a percentage of total government spending $[15$, 16].

So, the results of assessing the dynamics of HCI components revealed the priority of ensuring the survival of male children under 5 years of age and the subsequent indifference to their socialization. This phenomenon is not so much connected with the level of development of health care, but to a greater extent, reflects feminization in relation to changes in education, altering the principles of formation of society, family and, as a consequence, highlighting the dominant role of women. Tendency of the Russian educational system towards feminization is associated with the earlier formation of the female educational cluster.

\section{Conclusions}

As a result of the analysis of the HCI components growth rates, a special priority of state policy was revealed to ensure the survival of male children under 5 years of age and subsequent indifference to their socialization. The Russian educational system is acquiring the features of feminization - the dominance of women in social reality. A negative phenomenon of the Russian educational system was revealed in the form of a significant decrease in the growth of preschool juveniles of younger median age and preschool children of young age, the lag in the growth rate of government spending on education ( $\%$ of GDP) from spending on education as a percentage of total government spending.

In general, the priority of state policy to ensure survival of male children under 5 years of age and subsequent indifference to their socialization in the Russian educational system with clear signs of feminization escalate the problem of risk of gender bias. One of the ways to solve the issue of HCI growth may be restoration of an alternative educational institution based on sharpening attention to the man's place in the educational process.

\section{References}

1. Human Capital Index (HCI), The World Bank Group, All Rights Reserved (2020) https://datacatalog.worldbank.org/

2. S. G. Campbell, M. Üngör, Economic Modelling, 91, 43 (2020)

3. S. Vaitkevičius, R. Čiutienè, E. Meilienè, A. Savanevičienė, Procedia Economics and Finance, 23, 1641 (2015)

4. L.-T. Yeh, M.-L. Tseng, M. K. Lim, Journal of Cleaner Production, 250, 119584 (2020)

5. Y. Xu, A. Li., Journal of Computational and Applied Mathematics, 365, 112381 (2020)

6. L. Ma, X. Zhai, W. Zhong, Z.-X. Zhang, International Journal of Production Economics, 208, 241 (2019)

7. B. C. Olopade, H. Okodua, M. Oladosun, A. J. Asaleye, Heliyon, 5(8), e02279 (2019)

8. Z. Ahmed, M. M. Asghar, M. N. Malik, K. Nawaz, Resources Policy, 67, 101677 (2020)

9. Y. Yao, K. Ivanovski, J. Inekwe, R. Smyth, Energy Economics, 84, 104534 (2019)

10. C.-F. Chang, P. Wang, J.-T. Liu, Journal of Macroeconomics, 47(B), 214 (2016)

11. M. Gradstein, European Economic Review, 118, 148 (2019)

12. B. Égert, J. Botev, D. Turner, European Economic Review, 129, 103560 (2020) 
13. The UNESCO Institute for Statistics (UIS) (2020) http://data.uis.unesco.org/

14. V. V. Smirnov, V. L. Semenov, O. L. Taranova, T. V. Talanova, A. N. Zakharova, N. A. Ivanova, Proceedings of the 35th International Business Information Management Association Conference (IBIMA), Education Excellence and Innovation Management: A 2025 Vision to Sustain Economic Development during Global Challenges, 3731 (2020)

15. V. V. Smirnov, V. L. Semenov, E. N. Kadyshev, T. V. Talanova, A. N. Zakharova, N. G. Gubanova, Proceedings of the 35th International Business Information Management Association Conference (IBIMA), Education Excellence and Innovation Management: A 2025 Vision to Sustain Economic Development during Global Challenges, 3736 (2020)

16. V. V. Smirnov, A. N. Zakharova, T. V. Talanova, A. G. Abramova, S. A. Petunova, I. B. Getskina, M. N. Yaklashkin, Proceedings of the 35th International Business Information Management Association Conference (IBIMA) Education Excellence and Innovation Management: A 2025 Vision to Sustain Economic Development during Global Challenges, 7741 (2020) 